\title{
A model of the secular change of the geomagnetic field for Antarctica
}

\author{
J. M. Torta (1) ${ }^{*}$, A. De Santis (2), M. Chiappini (2), R.R.B. von Frese (3) \\ (1) Observatori de l'Ebre, CSIC, 43520 Roquetes (Tarragona), Spain. \\ (2) Istituto Naz. di Geofisica, V. Vigna Murata 605, 00143 Roma, Italy. \\ (3) Dept. of Geological Sciences, and Byrd Polar Research Center, The Ohio State University, Columbus, \\ $\mathrm{OH}$ 43210, USA.
}

In press on Tectonophysics

October 2000

* Corresponding author. Fax: +34 977 500511. E-mail: ebre.jmtorta@readysoft.es 


\title{
A model of the secular change of the geomagnetic field for Antarctica
}

\author{
J. M. Torta (1)*, A. De Santis (2), M. Chiappini (2), R.R.B. von Frese (3) \\ (1) Observatori de l'Ebre, CSIC, 43520 Roquetes (Tarragona), Spain. \\ (2) Istituto Naz. di Geofisica, V. Vigna Murata 605, 00143 Roma, Italy. \\ (3) Dept. of Geological Sciences, and Byrd Polar Research Center, The Ohio State University, Columbus, \\ $\mathrm{OH}$ 43210, USA.
}

\begin{abstract}
An improved model of geomagnetic secular change for the Antarctic was developed using observatory annual mean values measured in Antarctica during the last forty years. Spherical cap harmonic analysis with a power series time dependence was used to model spatial and temporal variations of main field differences at spatial wavelengths from 3000 to $13000 \mathrm{~km}$. The model was designed to facilitate merging satellite, airborne, marine and terrestrial magnetic data sets recorded at very different epochs in the Antarctic where significant annual geomagnetic changes have occurred. It improves the fit to observatory data by up to about 50\% relative to the International Geomagnetic Reference Field.
\end{abstract}

Keywords: Antarctica; spherical cap harmonic analysis; magnetic surveys; magnetic mapping; geomagnetic secular variation

\section{Introduction}

The need for improving the accuracy of the Antarctic geomagnetic core field models has been noted by the scientific community involved in south polar potential field applications (e.g., Chiappini et al., 1998). To this aim, the development of a potential field model by spherical cap harmonic analysis (SCHA) of magnetic data collected from

\footnotetext{
* Corresponding author. Fax: +34 977 500511. E-mail: ebre.jmtorta@readysoft.es
} 
observatories and ground, airborne, and satellite surveys was proposed (De Santis et al., 1999). With the proposed approach, a model may be obtained for a region that reflects spatial and temporal main field variations in greater detail and accuracy than is generally possible with standard global reference field models.

For a given epoch at auroral and polar cap latitudes, a three-component regional geomagnetic reference field model may be produced from vector satellite and/or aeromagnetic data that have been appropriately reduced for external magnetic field effects and represented at the ground level of the observatory data (e.g. Haines and Newitt, 1986; Newitt and Haines, 1989, 1991; Nevanlinna and Rynö, 1991; Nevanlinna et al., 1988). The secular variation (SV) of the field is required to reduce different data sets to a common epoch for effective anomaly determination.

The development of a SV model for updating magnetic data observed during the last 30 or 40 years in a region like Antarctica is especially problematic. At present, the only reliable data that can be used for producing the SV field model are observatory annual mean values and data from repeat stations. However, like in the Arctic, the distribution of these data in space and time is not ideal (De Santis et al., 1999). Hence we used the method of Haines (1993) to characterize SV by modeling main field differences. In general, this method permits the simultaneous representation of both the SV and main field, although for the present study we have focussed solely on generating the SV model from the available observatory data. 
The immediate application of a SV model over Antarctica lies in the production of a geomagnetic reference field that will facilitate the compilation of magnetic surveys by effectively translating them to a common epoch. The combination of the main field and SV model, obtained either by separate or joint analysis, will also facilitate the generation of charts of the geomagnetic field and its annual changes over the Antarctic territory for all the elements and epochs.

\section{Data}

For the present study, observatory annual mean values were used exclusively. Some of these data were collected over a limited period of the year (usually during Austral Summer) and the means correspond only to the periods with absolute references. Thus the means may still reflect relatively limited external field contamination due to solar cycle effects or seasonal biases in observatory data collected only during Austral Summer periods.

We processed the data measured south of latitude $60^{\circ} \mathrm{S}$ from 25 observatories (Figure 1) for the period 1960 to 1998, although at the time of this study, only three 1998 annual means had been forwarded to the World Data Centers from the corresponding agencies. Figure 1 shows that the spatial distribution of observatory data is limited mostly to the coast, which roughly defines a ring of stations at around latitude $70^{\circ} \mathrm{S}$. Additional stations are situated in the vicinity of the Antarctic Peninsula sector $\left(60^{\circ} \mathrm{S}-70^{\circ} \mathrm{S}\right)$ and in the Ross Sea sector $\left(70^{\circ} \mathrm{S}-80^{\circ} \mathrm{S}\right)$. Unfortunately, of those observatories situated inland, 
only Vostok (VOS, $78.45^{\circ} \mathrm{S}, 106.87^{\circ} \mathrm{E}$ ) was operated on a relatively continuous basis over the period of this study (Figure 2).

\section{Modeling}

The formula for the spherical cap harmonic (SCH) expansion holds not only for the potential, but also for any of its time derivatives. Hence, the SV of the field, which is defined as the first temporal derivative of the field, where the field is the negative gradient of the potential, can be fitted by taking the first differences of the geomagnetic field components as the observations (see Torta et al. (1993), eqs. 1-7). In the series of observatory annual means, the number of time gaps and their lengths are important factors, because time derivatives taken as simple first differences tend to yield unrealistic values of the SV. However, when the differences are taken relative to a fiducial observation, both the main field at epoch and the anomaly bias of the observatory are cancelled out because they are not functions of time (Haines, 1993). Taking the differences relative to the means over all data at each observatory also is a simple way of reducing the range of those differences that can reduce computational errors when the differences are expanded in power series or other temporal basis functions. In addition, in the equations below the $t$-values are scaled between -1 and +1 to make the $t^{q}$-terms reasonable in magnitude.

Therefore, following Haines (1993) and Haines and Newitt (1997), the $i$-th observation of the magnetic field at the $v$-th observatory at a time $t_{i v}$ may be written as:

$$
\vec{B}_{i v}(t)=\sum_{q=0}^{Q} \vec{b}_{q v} t_{i v}^{q}+\vec{\delta}_{v}+\vec{\varepsilon}_{i v},
$$


where $\vec{b}_{q v}$ are functions of position evaluated at the location of the $v$-th observation; $\vec{\delta}_{v}$ is the crustal anomaly at that location; and $\vec{\varepsilon}_{i v}$ is the measurement error. Taking the mean and the differences from the mean at each observatory yields:

$$
\vec{B}_{i v}(t)-\overline{\vec{B}}_{v}=\sum_{q=1}^{Q} \vec{b}_{q v}\left(t_{i v}^{q}-\overline{t_{v}^{q}}\right)+\vec{\varepsilon}_{i v}-\overrightarrow{\vec{\varepsilon}}_{v} .
$$

Here $\vec{b}_{q}$ is in fact a truncated spatial expansion, which includes $g$ - and $h$-coefficients that must be determined for the following north, east and vertically downward components of the SCH expansion:

$$
\begin{gathered}
b_{q X}=\sum_{k=1}^{K} \sum_{m=0}^{k}\left(\frac{a}{r}\right)^{n_{k}(m)+2} \frac{d P_{n_{k}(m)}^{m}(\cos \theta)}{d \theta}\left\{g_{k, q}^{m} \cos (m \phi)+h_{k, q}^{m} \sin (m \phi)\right\}, \\
b_{q Y}=\sum_{k=1}^{K} \sum_{m=1}^{k}\left(\frac{a}{r}\right)^{n_{k}(m)+2} \frac{m P_{n_{k}(m)}^{m}(\cos \theta)}{\sin \theta}\left\{g_{k, q}^{m} \sin (m \phi)-h_{k, q}^{m} \cos (m \phi)\right\}, \\
b_{q Z}=-\sum_{k=0}^{K} \sum_{m=0}^{k}\left(n_{k}(m)+1\right)\left(\frac{a}{r}\right)^{n_{k}(m)+2} P_{n_{k}(m)}^{m}(\cos \theta)\left\{g_{k, q}^{m} \cos (m \phi)+h_{k, q}^{m} \sin (m \phi)\right\} .
\end{gathered}
$$

The role of each function, index or variable in the above equations follows standard conventions (e.g., Torta et al., 1993; De Santis et al., 1999).

\section{Model analyses and results}

To establish effective modeling parameters, the three-component field was synthesized from the IGRF (Barton, 1997) at $5^{\circ}$-intervals of colatitude and longitude increments of 
$\left(5^{\circ} / \sin \theta\right)$ over the region south of $60^{\circ} \mathrm{S}$ at five year intervals from 1960 to 2000 . From the main field differences at each grid point, we found that the best fitting SCH expansion must be truncated at index 5 , and the time polynomial was optimal at degree 4 . Accordingly, a total of 144 coefficients are possible for the SCH expansion centered at the geographical South Pole with a half-angle of $30^{\circ}$.

Establishing maximum indices for fitting a series to data involves a compromise between maintaining small deviations of the predictions with respect to the data (i.e., a good fit) and acceptable (i.e., smooth) model behavior in areas of poor control. For example, the RMS deviations can be improved by increasing the maximum indices, but at the expense of unrealistically representing (i.e., overfitting) the spatial and temporal characteristics of the analyzed field. This problem is exacerbated in our application where the data are not well distributed inside the cap in either space or in time. Here, a model is required that fits the data well and also minimizes the production of high frequency (e.g., bull's eye) features over areas or periods with little or no data.

To resolve the tradeoff between data misfit and model smoothness or structure, we reduced the maximum spatial index to $K=4$, but maintained the maximum temporal index at $Q=4$, which reduced the total number of possible coefficients to 100 . The analysis was performed on 435 observatory differences available from the 25 observatories and 6 fictitious stations located on the cap boundary at $60^{\circ}$-intervals starting at $30^{\circ} \mathrm{E}$ longitude (see Figure 1). The fictitious stations were represented by data from the IGRF at five year intervals from 1960 to 2000 to guarantee a smooth transition across the 
continent-ocean boundary that generally lacks constraining data except in the Antarctic Peninsula-South Shetland Islands sector. The constraints imposed by the fictitious data on our model are relatively weak, because a variance ratio of 3 was taken in weighting these data relative to the observatory data. In our least-squares model, the data were assumed to be statistically isotropic and stationary. They were inversely weighted by the error variance $\left(\sigma^{2}\right)$, which was set to $\sigma=1$ for the observatory data and to $\sigma=\sqrt{3}$ for the fictitious data. The same error variances were used for processing the different vector components.

Out of the 100 coefficients, a total of 46 (Table 1 ) were statistically significant at an Flevel of 4 according to the stepwise selection procedure described in Haines and Torta (1994). Spatial wavelengths involved in this model range from approximately 3000 to $13000 \mathrm{~km}$ at the Earth's surface, which in the SCH expansion correspond to associated Legendre functions with degrees from 12.9083 and 3.1196, respectively. Table 2 demonstrates the fit of the SCH model to the Antarctic data, which is significantly improved relative to the IGRF predictions. These results were based on the RMS differences between the 435 observatory data and the corresponding predictions from the SCH and IGRF models.

Using the model coefficients, contour maps may be readily obtained for the changes of the magnetic elements over annual or other time intervals within the period of validity of the model. For example, figures 3, 4 and 5 give the 1996-1995 annual changes for the $X$, $Y$, and $Z$ components, respectively. In addition, figures 6, 7 and 8 give typical examples 
at various observatories of how well the SCH model follows the annual means over their respective time spans.

To investigate the validity of the model in the vast regions without observatories, we produced another SCH model where the strongly variable Vostok (VOS) data were excluded. The favorable comparison of the two SCH models to the VOS data that is shown in figures 9,10 , and 11 certainly helps to demonstrate the robustness of our approach. For the SCH model based on all available data, the RMS fits to the $X, Y$, and $Z$ components at VOS were 51, 45 and $30 \mathrm{nT}$, respectively, whereas for the second SCH model, they were 84, 60 and $42 \mathrm{nT}$, respectively. Note that the differences in the model predictions are predominantly limited to the ends of the 39-year time span where the VOS data are especially scattered.

\section{Conclusions}

The comparison of the input main field differences with the calculated ones in Table 2 shows how well the SCH model reproduces the SV. Relative to the IGRF, the SCH model gives $X$-, $Y$-, and $Z$-component predictions that are improved by roughly $29 \%, 43 \%$, and 53\%, respectively. Overall, the SCH model provides a 43\% improvement in predicting main field differences in the Antarctic. Thus the SCH model provides for better estimates of temporal and spatial detail, and more accurate updates of survey data for SV. In addition, the use of a continuous function in time to characterize SV is more realistic than interpolating between IGRF models that are produced every 5 years. Moreover, analyzing 
main field differences relative to the observatory averages is definitely more robust than fitting changes derived by numerical differentiation.

Future efforts will focus on modeling simultaneously the SV and the main field using data from the Ørsted satellite that is presently in orbit. The external fields will be removed using correlation filters to extract coherent internal field signals from adjacent passes and maps produced at varying local magnetic times (Alsdorf et al., 1994). These data may be merged with observatory, ground survey, and any other reliable data sets (e.g., Magsat, airborne or balloon) during the given time span by weighting each data set according to the reciprocal of its estimated error variance as suggested by Haines and Newitt (1997).

In addition to the Magsat and Ørsted vector magnetic data, the scalar data from these satellites also will be used because the models made from polar data are not subject to the Backus effect. Relative to the vector data, the scalar data are also minimally affected by attitude determination errors, and hence are less influenced by the external field-aligned current systems. Furthermore, the nonlinear programming for incorporating scalar data in the SCHA has already been developed (Haines and Newitt, 1997).

Merging satellite and other reliable data as proposed above can yield improved SCH models of Antarctic SV to better exploit the limited observatory data in processing magnetic surveys for lithospheric components. In addition, improved core field 
coefficients can result from the augmented spatial and temporal coverage provided by SCH models of Antarctic secular change.

\section{Acknowledgements}

The authors thank the Geological Survey of Canada for the codes to perform the SCHA by modeling main field differences, and G.V. Haines for correcting some bugs that appeared in the application of the code to a spherical cap at the South Pole. The observatory data were made available from the World Data Centre C1 for Geomagnetism (Edinburgh). The comments of J. M. Quinn, T. J. Sabaka and of an anonymous referee considerably improved the manuscript. This research was partially funded by the Italian Programma Nazionale di Ricerche in Antartide (PNRA) and by the Spanish Programa Nacional de Investigación en la Antártida (PNIA, CICYT, Project No. ANT98-0886).

\section{References}

Alsdorf, D.E., von Frese, R.R.B., Arkani-Hamed, J., Noltimier, H.C., 1994. Separation of lithospheric, external, and core components of the south polar geomagnetic field at satellite altitudes, J. Geophys. Res., 99, 4655-4668.

Barton, C.E., 1997. International Geomagnetic Reference Field: The Seventh Generation, J. Geomag. Geoelectr., 49, 123-148.

Chiappini, M., von Frese, R.R.B., Ferris, J., 1998. Effort to develop magnetic anomaly database aids Antarctic research, EOS Trans. Am. Geophys. Union 79, 290. 
De Santis, A., Chiappini, M., Torta, J.M., von Frese, R.R.B., 1999. Development of an improved geomagnetic reference field of Antarctica, Annali di Geofisica 42, 265 270.

Haines, G.V., 1993. Modelling geomagnetic secular variation by main-field differences, Geophys. J. Int. 114, 490-500.

Haines, G.V., Newitt, L.R., 1986. Canadian Geomagnetic Reference Field 1985, J. Geomag. Geoelectr. 38, 895-921.

Haines, G.V., Newitt, L.R., 1997. The Canadian Geomagnetic Reference Field 1995, J. Geomag. Geoelectr., 49, 317-336.

Haines, G.V., Torta, J.M. 1994. Determination of equivalent current sources from spherical cap harmonic models of geomagnetic field variations. Geophys. J. Int. 118, 499-514.

McLean, S.J., Meyers, K.D., Morris, L.D, Davis, W.M., 1995. A report on geomagnetic observatories. World Data Center-A for Solid Earth Geophysics, Rep. SE-53. Boulder, CO, 110 pp.

Nevanlinna, H., Rynö, J., 1991. Spherical cap harmonic model of the Scandinavian geomagnetic field for 1990. HHI-Rep., 22, 106.

Nevanlinna, H., Rynö, J., Haines, G.V., Borg, K., 1988. Spherical cap harmonic analysis applied to the Scandinavian geomagnetic field 1985.0. Deut. Hydro. Zeits. 41, 177-186. 
Newitt, L.R., Haines, G.V., 1989. A Canadian Geomagnetic Reference Field for Epoch 1987.5. J. Geomagn. Geoelectr., 41, 249-260.

Newitt, L.R., Haines, G.V., 1991. The Canadian Geomagnetic Reference Field 1990. In: Current Research, Part E, Geological Survey of Canada, paper 91-1E, 275-281.

Torta, J.M., García, A., De Santis, A. 1993. A geomagnetic reference field for Spain at 1990. J. Geomag. Geoelectr., 45, 573-588. 


\section{Figure captions}

Fig. 1. Geomagnetic observatories used in the analysis identified by their three-letter IAGA codes (McLean et al., 1995). Also shown are the fictitious data stations (solid dots) on the cap boundary.

Fig. 2. Temporal distribution of the observatory annual means.

Fig. 3. Annual change of the $X$ component (1996 - 1995) in nT/year obtained from the SCH model. The boundary of the spherical cap is also shown.

Fig. 4. As in Fig. 3, but for $Y$.

Fig. 5. As in Fig. 3, but for $Z$.

Fig. 6. Comparison of secular change in nT for the $X$ component derived from the SCH model (lines) and observatory annual means (symbols) at different observatories. All values are plotted relative to their respective mean over the time interval.

Fig. 7. As in Fig. 6, but for $Y$.

Fig. 8. As in Fig. 6, but for $Z$.

Fig. 9. Comparison of secular change for $X$ in nT at VOS from the final SCH model (solid line) and another SCH model where VOS was excluded in the analysis (dashed line). Also shown are the observatory annual means (symbols) relative to their respective mean over the time interval .

Fig. 10. As in Fig. 9, but for $Y$.

Fig. 11. As in Fig. 9, but for $Z$. 


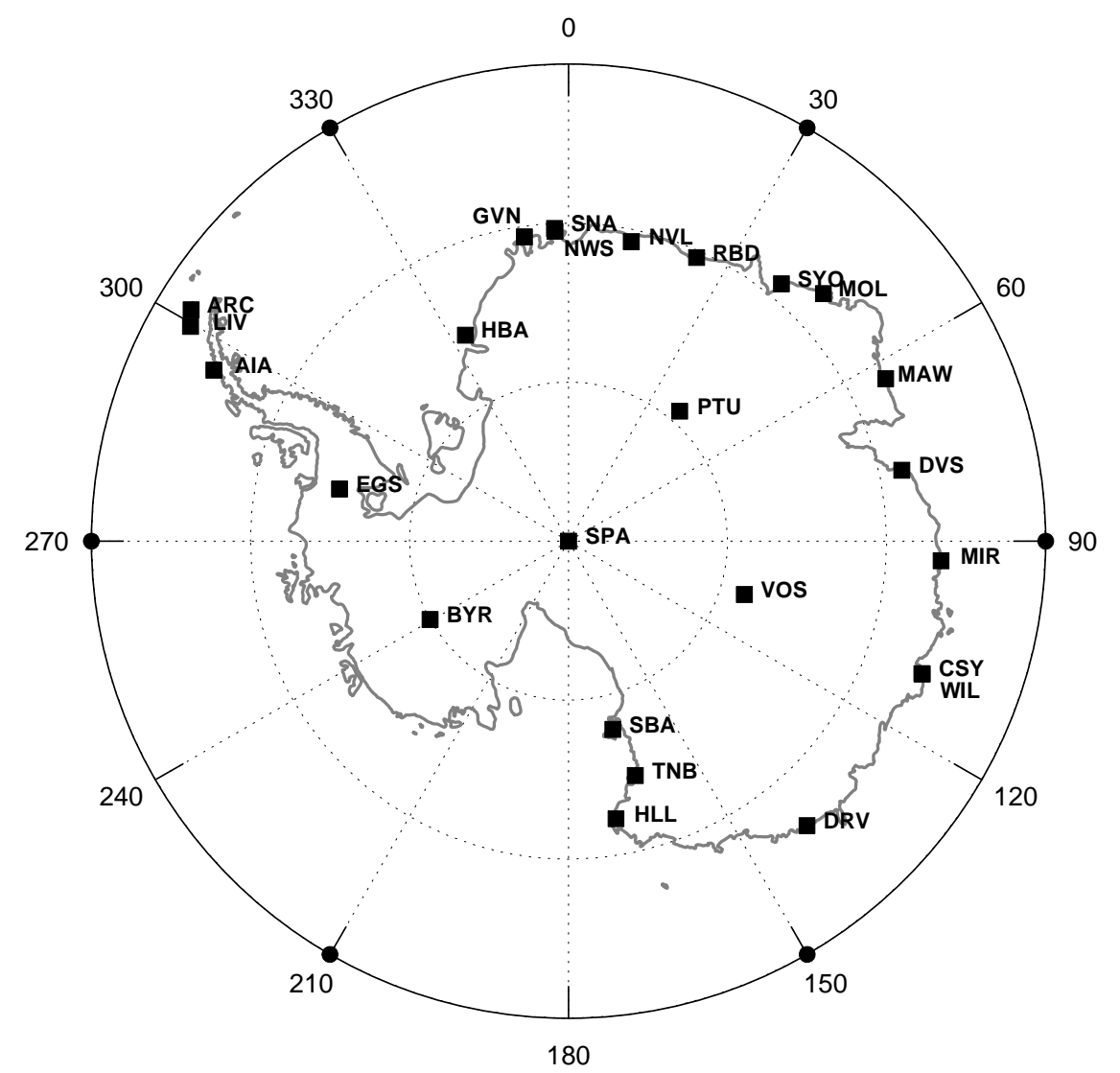

Fig. 1

Fig. 2

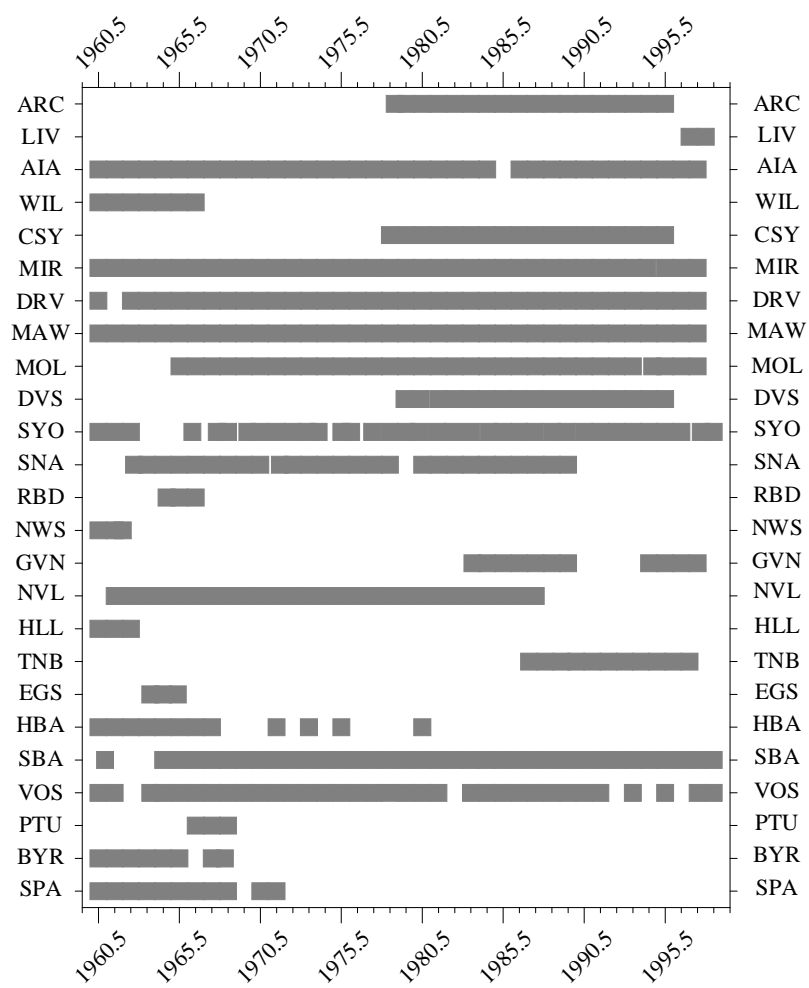


Fig.3

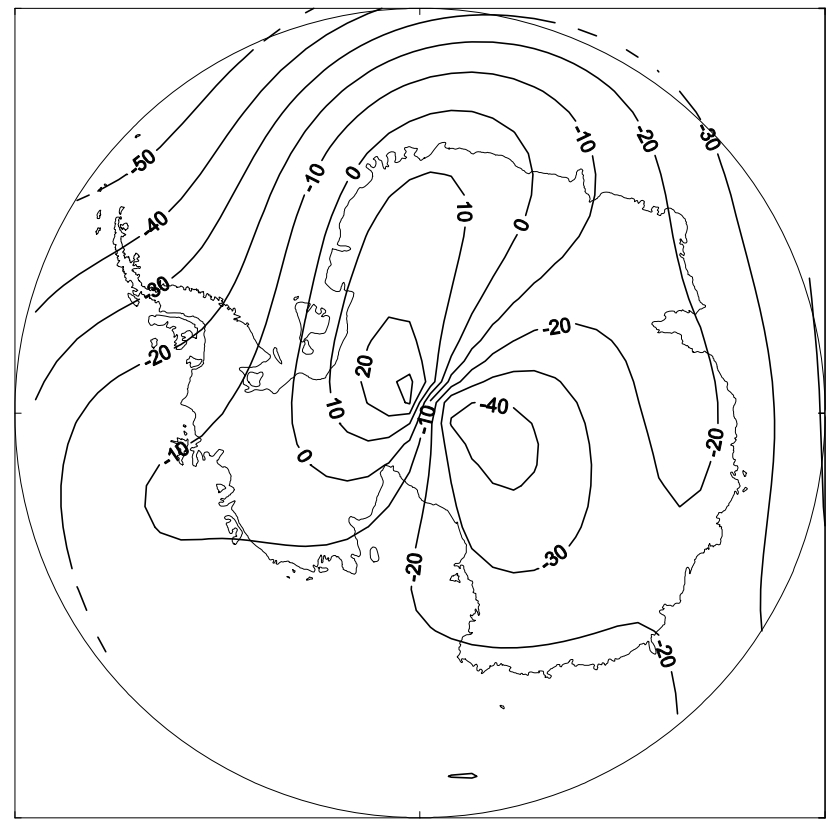

Fig.4

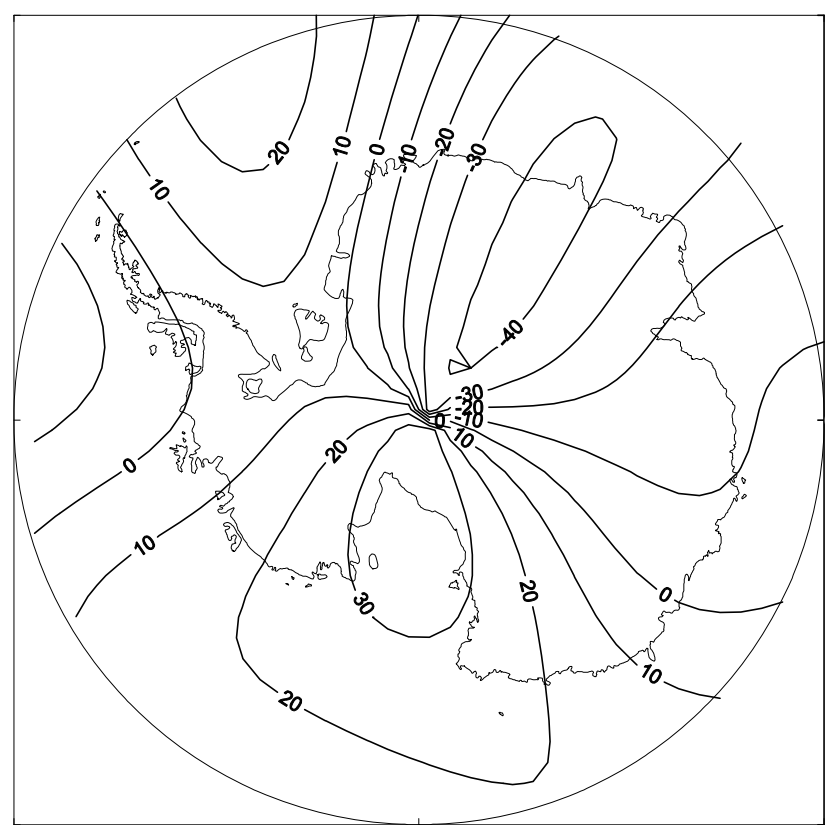

Fig.5

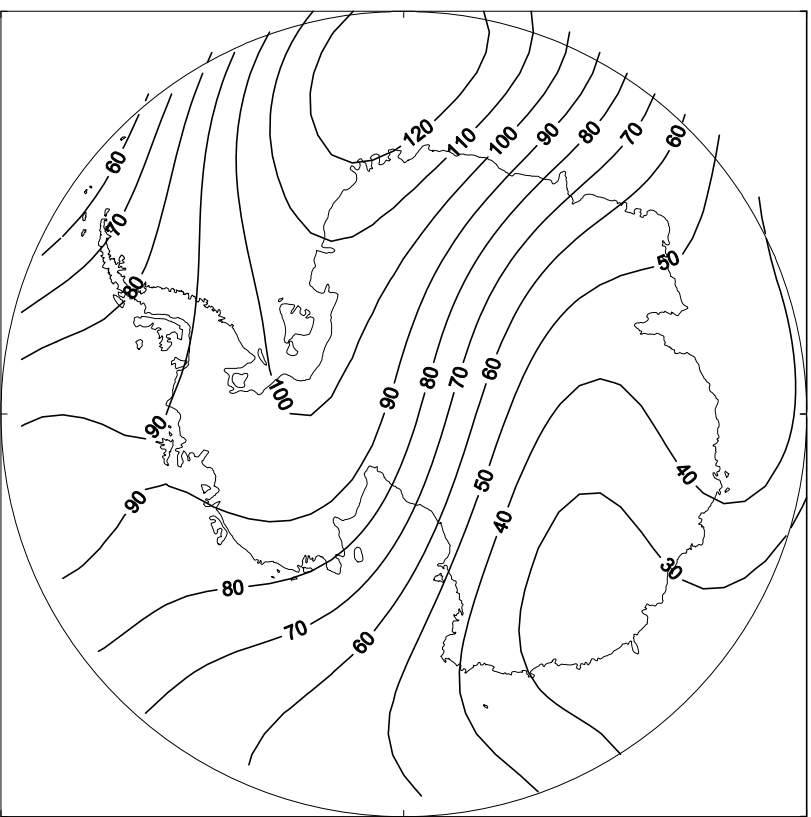




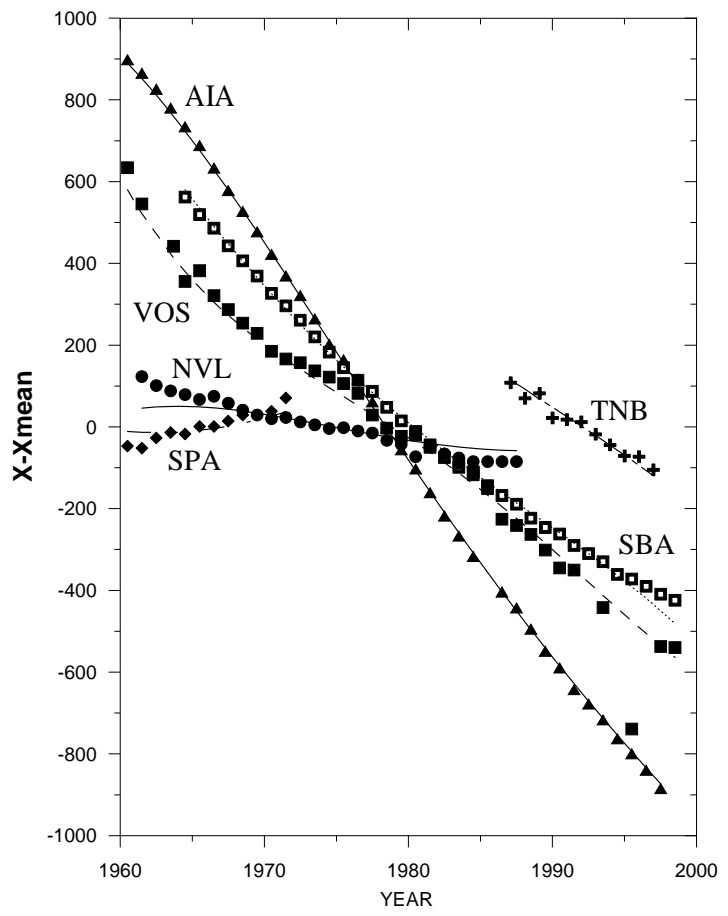

Fig.6

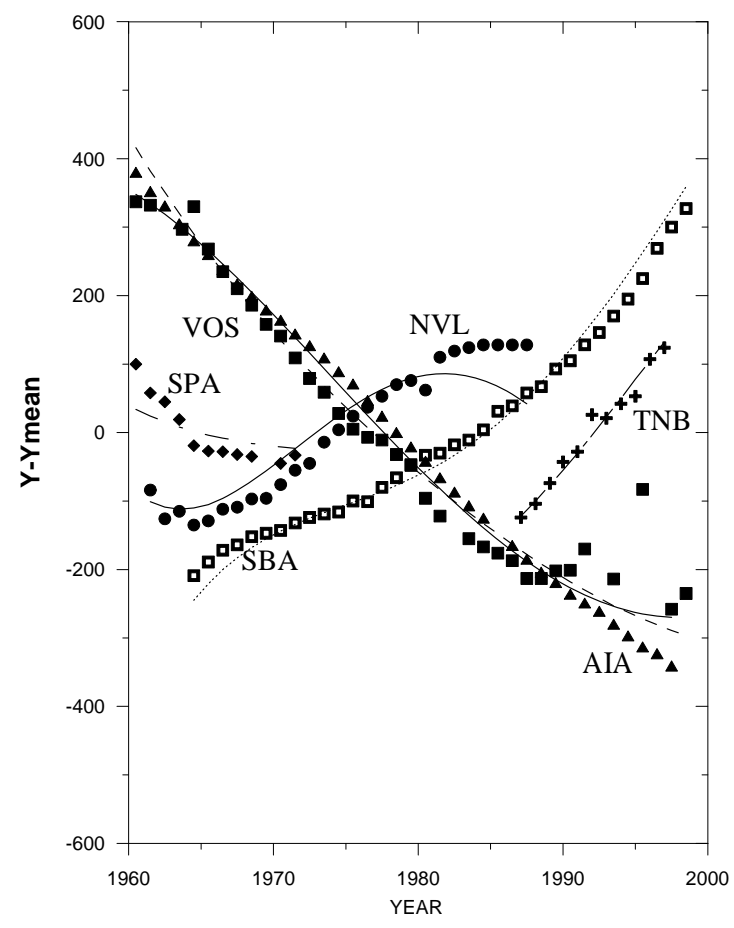

Fig.7

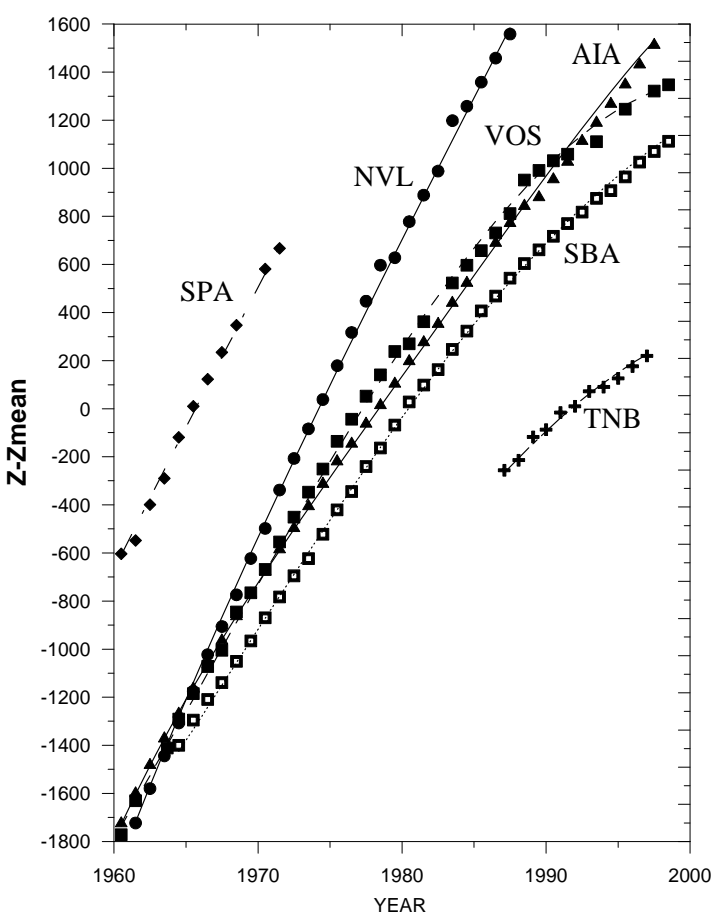

Fig.8 

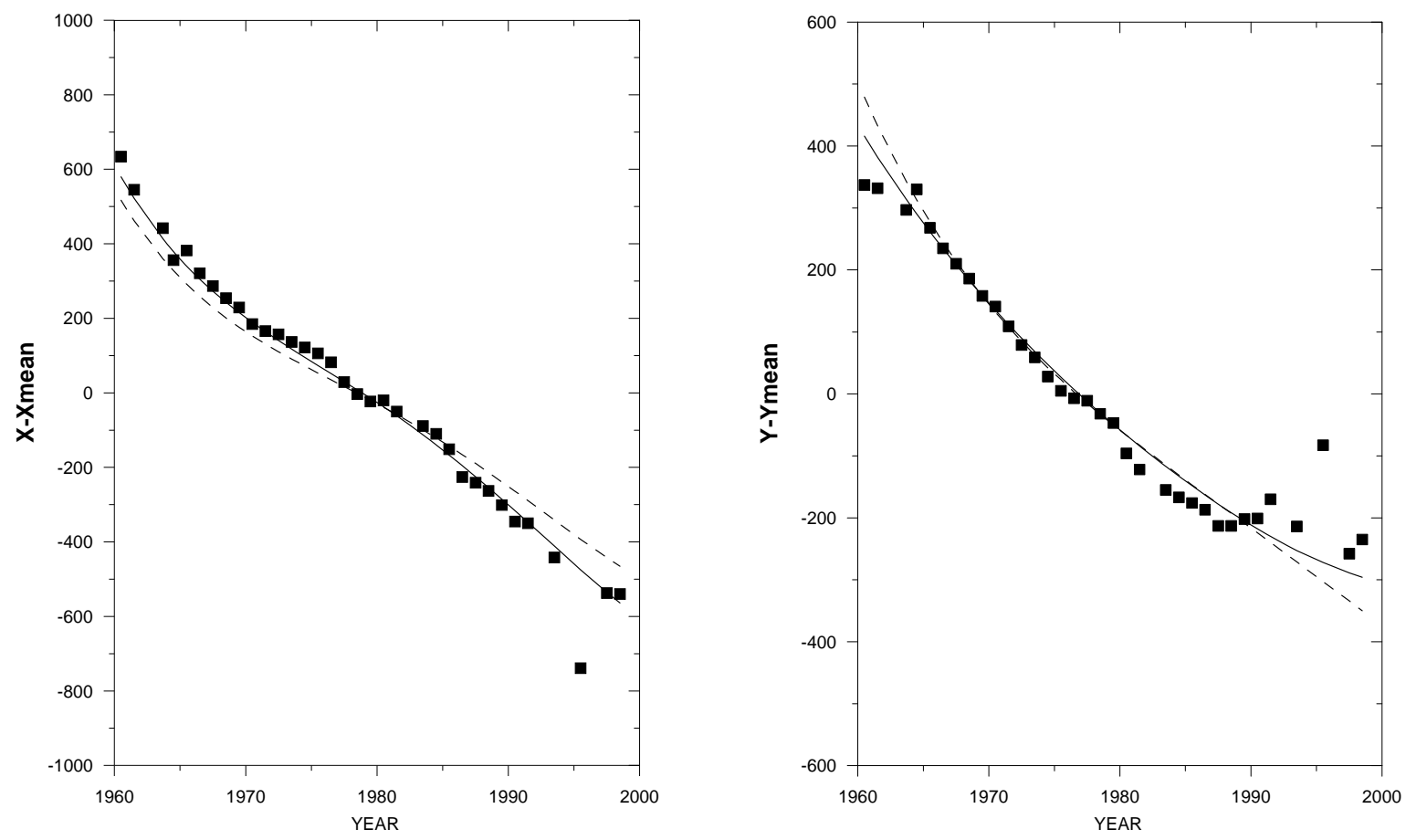

Fig.9

Fig.10

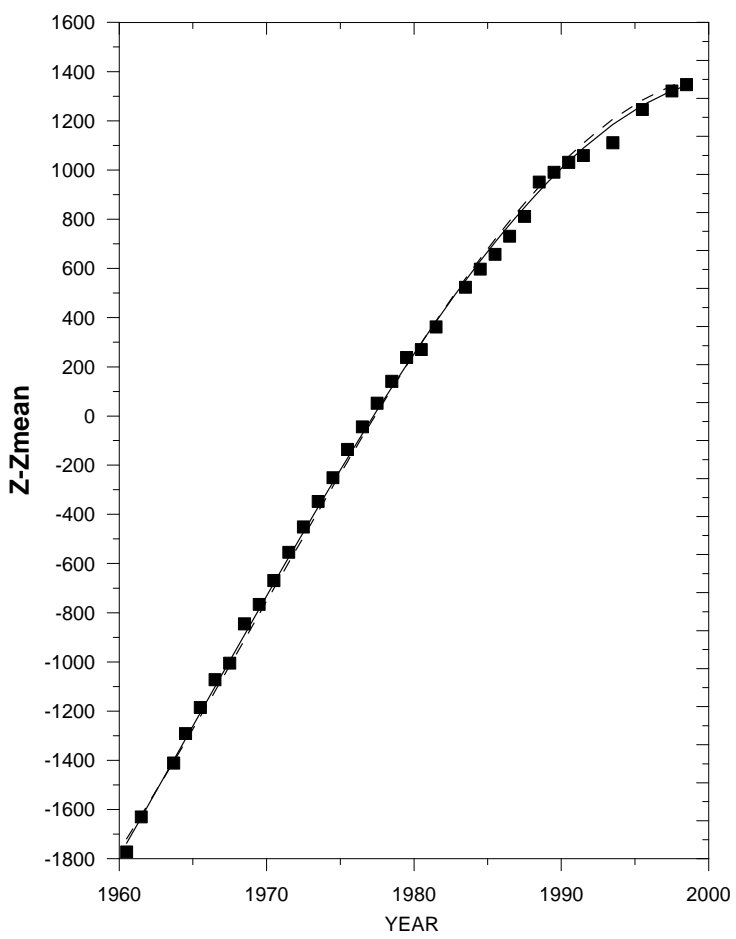

Fig.11 
Table 1

Coefficients of the SCH fit to Antarctic observatory main field differences

\begin{tabular}{|c|c|c|c|c|c|c|c|c|c|c|}
\hline k & $\mathrm{m}$ & $\mathrm{n}_{\mathrm{k}}(\mathrm{m})$ & $g_{k, 1}^{m}$ & $h_{k, 1}^{m}$ & $g_{k, 2}^{m}$ & $h_{k, 2}^{m}$ & $g_{k, 3}^{m}$ & $h_{k, 3}^{m}$ & $g_{k, 4}^{m}$ & $h_{k, 4}^{m}$ \\
\hline$\odot$ & $\odot$ & .0000 & -1054.956 & & 128.606 & & 66.546 & & .000 & \\
\hline 1 & $\odot$ & 4.0837 & -366.136 & & 32.151 & & .000 & & .000 & \\
\hline 1 & 1 & 3.1196 & 66.785 & 67.147 &.$\odot \odot \odot$ & 77.042 & $.00 \odot$ & 49.494 & $.0 \odot \odot$ & -64.720 \\
\hline 2 & $\odot$ & 6.8354 & 142.014 & & $.00 \odot$ & & $.0 \odot \odot$ & & $.0 \odot \odot$ & \\
\hline 2 & 1 & 6.8354 & 32.841 & -19.609 & .000 & .000 & 23.365 & .000 & .000 & 19.402 \\
\hline 2 & 2 & 5.4928 & .000 & 142.282 & -60.464 & -44.782 & -33.190 & .000 & 37.039 & .000 \\
\hline 3 & $\odot$ & 10.0386 & -28.177 & & .000 & & $.0 \odot \odot$ & & $.00 \odot$ & \\
\hline 3 & 1 & 9.7121 & $.00 \odot$ & 16.826 & 14.293 & .000 & -28.560 & .000 & .000 & $.0 \odot \odot$ \\
\hline 3 & 2 & 9.3733 & 6.451 & -43.816 & $.0 \odot \odot$ & $.0 \odot \odot$ & 10.473 & -16.040 & $.0 \odot \odot$ & 24.043 \\
\hline 3 & 3 & 7.7524 & 56.027 & -33.554 &.$\odot \odot \odot$ & 9.952 &.$\odot \odot \odot$ & .000 & $.0 \odot \odot$ & $.0 \odot \odot$ \\
\hline 4 & $\odot$ & 12.9083 & $.0 \odot \odot$ & & -5.028 & & $.0 \odot \odot$ & &.$\odot \odot \odot$ & \\
\hline 4 & 1 & 12.9083 & .000 & .000 & .000 & .000 & .000 & .000 & .000 & 5.928 \\
\hline 4 & 2 & 12.3720 & .000 & .000 & .000 & .000 & .000 & 33.273 & -8.216 & -26.338 \\
\hline 4 & 3 & 11.8074 & -24.689 & 8.664 & $.0 \odot \odot$ & 7.235 & 13.244 & .000 & .000 & .000 \\
\hline 4 & 4 & 9.9589 & -27.450 & 23.649 & -23.905 &.$\odot \odot \odot$ &.$\odot \odot \odot$ & -16.467 & 16.443 &.$\odot \odot \odot$ \\
\hline
\end{tabular}

Table 2

RMS fits to observatory differences

\begin{tabular}{lccccc}
\hline & No. of differences & X (nT) & Y (nT) & Z (nT) & Overall \\
\hline IGRF & 435 & 45.4 & 56.7 & 106.9 & 74.6 \\
SCH Model & 435 & 32.2 & 42.4 & 50.2 & 42.2 \\
\hline
\end{tabular}

